\title{
Analysis of Demographic Characteristics and Treatment Outcome of Breast Cancer Patients in a Tertiary Cancer Centre
}

\author{
Arumugam Velappan ${ }^{1}$, Deepa Shumugam ${ }^{2}$ \\ ${ }^{I}$ (Department of Medical Oncology, Tirunelveli Medical College, TN Dr MGR Medical University, India) \\ ${ }_{2}^{2}$ (Department of Surgical Oncology, Tirunelveli Medical College, TN Dr MGR Medical University, India)
}

\begin{abstract}
Breast cancer is the second most common cancer in the world and the most common cancer among women. In this retrospective study data regarding demographic characteristics and treatment outcome was collected from all breast cancer patients for a period of 15 years. More than 50\% of patients were diagnosed at a later stage. Triple negative breast cancers constituted about 25\%. Five year DFS and OS were $67.4 \%$ and $78.7 \%$ respectively. An organized breast cancer screening program is the need of the hour.
\end{abstract}

Keywords: Breast cancer, Demographic data, breast cancer screening

\section{Introduction}

Breast cancer is the most common female cancer worldwide representing nearly a quarter (25\%) of all cancers with an estimated 1.67 million new cancer cases diagnosed in $2012^{[1]}$. Now breast cancer has surpassed cervical cancer and is the most common cancer of woman in India ${ }^{[2]}$. A significant rise in magnitude of breast cancer was observed in the previous two decades in most of the Indian registries ${ }^{[3]}$.

\section{Materials And Methods}

Data was collected from the records of radiotherapy department and medical oncology department at the Regional Cancer Centre, Tirunelveli Medical College Hospital, Tirunelveli, Tamilnadu. This retrospective study includes 1528 patients treated for carcinoma breast at this centre between January 2002 and December 2016. The demographic characteristics and treatment outcome of all 1528 patients were analysed.

\section{Results}

The median age at presentation was 49 years (24-88 years). Patients under the age of $<35$ years constituted about $12.4 \%$ in our institution. Among the 1528 patients, 464 women $(30.36 \%)$ were premenopausal and $1064(69.63 \%)$ postmenopausal at the time of diagnosis. Patients from rural areas constituted about $57.2 \%$ whereas only $42.8 \%$ came from urban areas. Family history of breast cancer was positive in $4.2 \%$ of patients. The commonest symptom was presence of breast lump (96\%). Other symptoms were pain (17.5\%) and nipple discharge (4.5\%). An analysis of the Immunohistochemistry status is shown below:

\begin{tabular}{|c|c|}
\hline IHC Status & Percentage \\
\hline ER +ve PR +ve Her 2 neg & 30.68 \\
\hline ER neg PR neg Her 2 neu 3+ & 25 \\
\hline ER +ve PR +ve Her 2 neu 3+ & 19.32 \\
\hline Triple Negative & 25 \\
\hline
\end{tabular}

More than 50\% patients presented with stage III and stage IV disease in our institution. Stage I, II, III and IV comprised 6, 37, 42 and 15 percentage respectively. At a median follow-up of 60 months 313 (32.6\%) out of 1303 patients who had non-metastatic disease had relapsed (systemic 256, loco-regional 57) and 204 patients $(21.3 \%)$ had died. Five year DFS and OS were $67.4 \%$ and $78.7 \%$ respectively. 
1. Incidence - Stage wise

\section{Figures}

\section{PERCENTAGE}

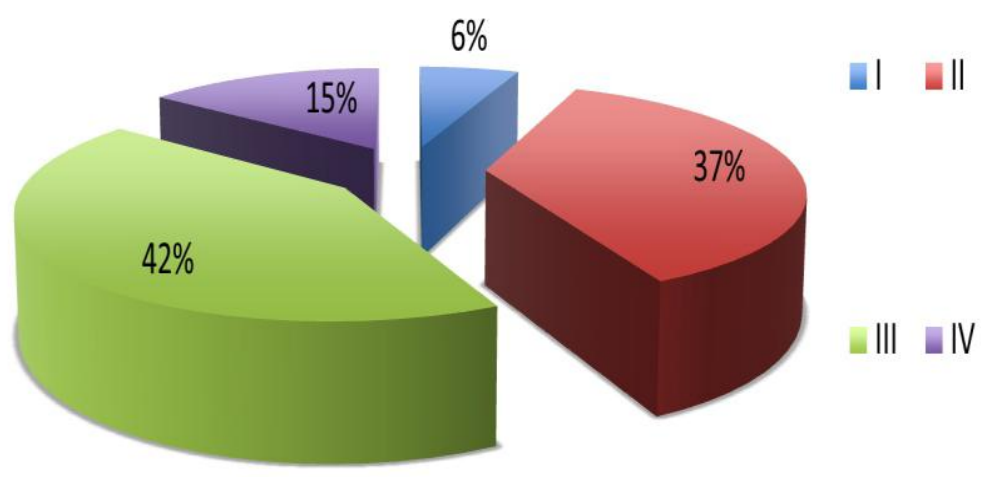

2. Symptoms

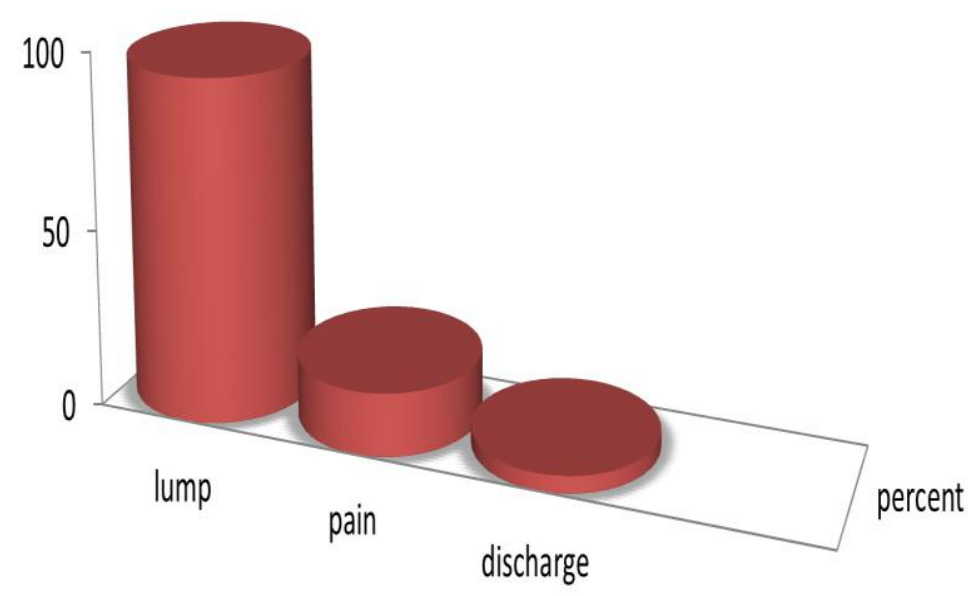

3. Annual Incidence

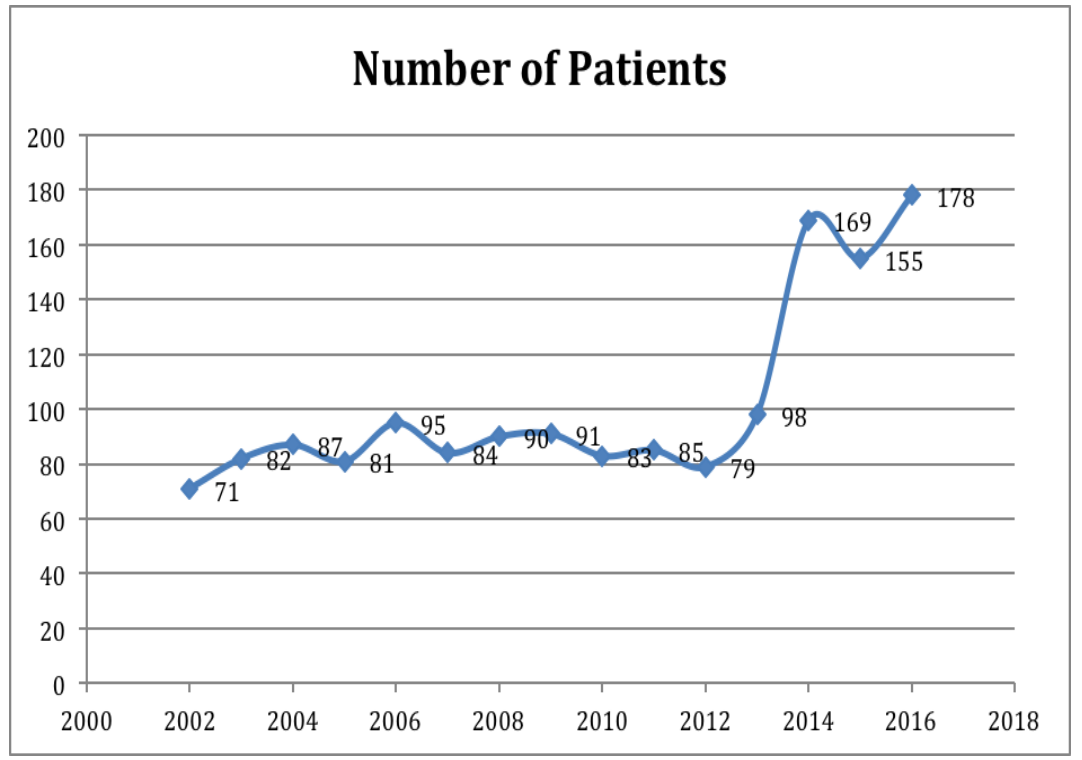




\title{
4. Menopausal Status
}

\section{PERCENTAGE}

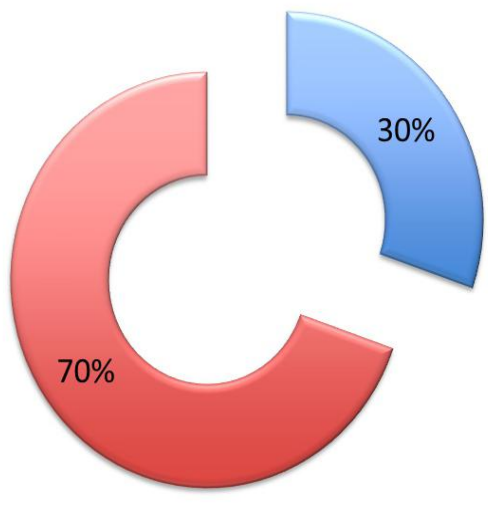

\author{
$\square$ PRE MENOPAUSAL
}

$\square$ POST MENOPAUSAL

\section{Discussion}

India is facing a challenging situation due to rising incidence of breast cancer. There was $11.54 \%$ increase in incidence and $13.82 \%$ increase in mortality due to breast cancer during 2008-2012 ${ }^{[4]}$. In the major Indian cancer registries breast cancer has achieved the top rank among the female cancers during the same period. The reason is increasing urbanization and westernization associated with changing lifestyle and food habits. Studies show that the disease peaks at 40- 50 years in Indian women with a peak relative proportion between 45 and 49 years ${ }^{[5,6]}$ which is similar to the median age of presentation at our institution which is 49 years. Indian women having breast cancer are found a decade younger in comparison to western women ${ }^{[7,8]}$. This suggests that breast cancer occurs at a younger premenopausal age in India. But in our study majority of cases were postmenopausal.

Women from rural areas lack awareness and facilities for early diagnosis. So they are diagnosed in late and advanced stages ${ }^{[4]}$. In our study more than $50 \%$ women were diagnosed in stage III and stage IV there by compromising the survival. Various studies in India show that $45.7 \%$ cases are diagnosed at an advanced stage whereas in the western countries breast cancer is diagnosed in early stages ${ }^{[9,10]}$. Interestingly a rural life style has been suggested to be associated with a decreased risk of breast cancer as compared to their urban counterparts by Nagarani et al. Breast cancers in younger women are usually more aggressive and they tend to present at a higher stage and grade than late-onset cancers ${ }^{[12]}$. Younger women have denser breast tissues and it makes them less amenable to routine screening procedures. Various studies have suggested that the prevalence of triple negative breast cancers is higher in Indian population as compared to the western population ${ }^{[14,15]}$. Sandhu et al in their meta-analysis state that the prevalence of triple negative breast cancer in India is 27 to $35 \%$, whereas in our study it is $25 \%{ }^{[14]}$.

Among Indian breast cancer patients the frequency of mutations in various studies is 2.9 to $24 \%{ }^{[16]}$. In our study $4.2 \%$ patients gave a positive family history of breast cancer. Genetic analysis was not possible in our study because of the cost factor. Sathwara et al in their review article estimate that the DFS for breast cancer in India is 41 to $76 \%$ and OS 40 to $62 \%{ }^{[17]}$. In our study the OS is higher $(78.7 \%)$. It may be attributed to the conduct of the study at a tertiary cancer institution.

\section{Conclusion}

Breast cancer is an emerging health problem in India. Diagnosis at an advanced stage is a major concern. Education, awareness campaigns, better access to diagnostic resources, availability of higher standards of health care, use of breast self examination and screening mammography if implemented universally would go a long way towards increasing early diagnosis and improved survival.

Conflicts of Interest: Nil

Acknowledgements: Nil

\section{References}

[1]. FerlayJ,SoerjomataramI,DikshitRetal.Cancerincidence and mortality worldwide: sources, methods and major pat- terns in GLOBOCAN 2012. Int J Cancer 2015; 136: E359- 86.

[2]. Kaarthigeyan K. Cervical cancer in India and HPV vaccina- tion. Indian J Med Paediatr Oncol 2012; 33: 7-12.

[3]. Ali I, Wani WA, Saleem K. Cancer scenario in India with future perspectives. Cancer Therapy 2011; 8: 56-70. 
[4]. Malvia, S., Bagadi, S. A., Dubey, U. S. and Saxena, S. (2017), Epidemiology of breast cancer in Indian women. Asia-Pac J Clin Oncol. doi:10.1111/ajco.12661

[5]. Chopra B, Kaur V, Singh K. Age shift: Breast cancer is occur- ring in younger age groups: Is it true? Clin Cancer Investig J 2014; 3: $526-9$.

[6]. Anonymous. National Cancer Registry Programme 2007- 2011. Indian Council of Medical Research (ICMR), Bangalore, India 2013.

[7]. Chopra B, Kaur V, Singh K, Verma M, Singh S, Singh A. Age shift: breast cancer is occurring in younger age groups-is it true? Clin Cancer Investig J 2014; 3: 526-29.

[8]. Thangjam S, Laishram RS, Debnath K. Breast carcinoma in young females below the age of 40 years: a histopathologi- cal perspective. South Asian J Cancer 2014; 3: 97-100.

[9]. Kakarala M, Rozek L, Cote M, Liyanage S, Brenner DE. Breast cancer histology and receptor status characterization in Asian Indian and Pakistani women in the U.S.: a SEER analysis. BMC Cancer 2010; 10: 191.

[10]. Leong SP, Shen ZZ, Liu TJ et al. Is breast cancer the same disease in Asian and Western countries? World J Surg 2010; 34: 230824.

[11]. Nagrani RT, Budukh A, Koyande S, Panse NS, Mhatre SS, Badwe R. Rural urban differences in breast cancer in India. Indian J Cancer 2014; 51: 277-81.

[12]. Anders CK, Hsu DS, Broadwater G et al. Young age at diag-nosis correlates with worse prognosis and defines a subset of breast cancers with shared patterns of gene expression. J Clin Oncol 2008; 26: 3324-30.

[13]. Das ULK, Lokanatha D. Breast Cancer in Women of Younger than 35 Years: A Single Center Study. J Mol Biomark Diagn 2015; 6: 261 .

[14]. Sandhu GS, Erqou S, Patterson H, Mathew A. Prevalence of triple-negative breast cancer in India: systematic review and metaanalysis. J Global Oncol 2016; 2: 412-21.

[15]. Ghosh J, Gupta S, Desai S et al. Estrogen, progesterone and HER2 receptor expression in breast tumors of patients, and their usage of HER2-targeted therapy, in a tertiary care cen- tre in India. Indian J Cancer 2011; 48: 391-6.

[16]. aidyanathan K, Lakhotia S, Ravishankar HM, Tabassum U, Mukherjee G, Somasundaram K. BRCA1 and BRCA2 germline mutation analysis among Indian women from South India: identification of four novel mutations and high-frequency occurrence of 185delAG mutation. J Biosci 2009; 34: 415-22.

[17]. sathwara, Jignasa; BOBDEY, Saurabh; B., Ganesh. Breast cancer survival studies in India: a review. International Journal of Research in Medical Sciences, [S.1.], v. 4, n. 8, p. 3102-3108, jan. 2017. ISSN 2320-6012. 